\title{
El cuerpo como dispositivo didáctico en la formación inicial docente en artes visuales para enseñanza secundaria
}

\author{
The body as a didactic dispositive in the initial teacher training in \\ visual art for secondary education
}

Luis Claudio CORTES. Universidad Metropolitana de Ciencias de la Educación (Chile).luis.cortes@umce.cl

Noemi GRINSPUN. Universidad Metropolitana de Ciencias de la Educación (Chile). noemi.grinspun@umce.cl

Sandra MEDINA. Universidad de La Laguna (España). sandramedinagarbo@gmail.com

Claudio Humberto OYARZÚN. Universidad de Talca (Chile).coyach@hotmail.com

Resumen. El presente artículo corresponde a una experiencia pedagógica implementada al interior de un programa de formación de profesores/as en artes visuales, cuyo futuro contexto de desempeño laboral son los niveles de enseñanza secundaria en el contexto escolar chileno. Su objetivo principal es reflexionar teóricamente en torno al cuerpo y sus posibilidades pedagógicas, a partir de la implementación de estrategias de enseñanza y aprendizaje de las artes visuales que involucran la practica corporal como dispositivo didáctico. Bajo una metodología de Proyectos de Aprendizaje Expresivos define tres talleres teóricos/prácticos en torno al cuerpo al interior de un programa formación de profesores/as en artes visuales en Chile. Tras la implementación de cada taller, describe la reflexión de la práctica corporal con el ámbito teórico de la política del cuerpo, la corporeización de la identidad profesional y la cognición corporeizada. A modo de conclusión, permite reflexionar en torno al tránsito de una enseñanza disciplinar de las artes visuales hacia su integración interdisciplinar, entrelazando el ámbito de las humanidades con la cognición humana corporeizada. Finalmente sugiere tres talleres interdisciplinares que entrelazan literatura, teatro y cine, a partir del lenguaje y expresión corporal para programas de formación inicial de profesores/as en artes visuales. 
Palabras clave: cuerpo; artes visuales; teoría del arte; formación de docentes.

\begin{abstract}
This article is based on a pedagogical experience implemented within a visual arts teacher training program, whose future work context will be the secondary education levels in the Chilean school context. Its main objective is to theoretically reflect about the body and its pedagogical possibilities. Since the implementation of a program of visual art teaching and learning that includes the body as a didactic dispositive. Under a methodology of a Learning-Expressive Project were defined three theoretical practical workshops about the body within a visual art teachers training program in Chile. After every workshop it was described the reflection of corporal practice with the theoretical scope of the body politics, the embodiment of professional identity and embodied cognition. As a conclusion, it allows us to reflect on the transition from a disciplinary teaching of the visual arts towards its interdisciplinary integration, intertwining the field of the humanities with embodied human cognition. Finally, three interdisciplinary workshops are suggested that intertwine literature, theater and cinema, based on body language and expression for visual arts teachers initial training programs.
\end{abstract}

Keywords: body; visual arts; art theory; teachers training

\title{
Introducción: problematización y revisión literaria
}

La acción pedagógica de futuros profesores/as en artes visuales, durante sus prácticas profesionales en niveles de enseñanza secundaria en el contexto escolar chileno, se han centrado principalmente en el aprendizaje artístico visual en torno a la creación de objetos de arte (Cortés, 2018; Cortés y Grinspun, 2019). Uno de los principales factores que inciden en dichas prácticas pedagógicas, se debe en gran medida a la débil relación interdisciplinar establecida entre los lenguajes artísticos durante su formación inicial. Evidenciando escaza o nula conexión con la creatividad y el desarrollo del lenguaje corporal, en el entendido que el cuerpo como dispositivo didáctico ha permitido integrar ámbitos teóricos de otras disciplinas en la enseñanza de las artes visuales (Horn, 2009; Marshall, 2014). Conduciendo la formación artística en Chile hacia su desaparición (Cárdenas, Lagos y Figueroa, 2016), producto de su homogeneización disciplinar en la formación inicial docente. Así como ante la ausencia de especializaciones y/o menciones en esta área (Orbeta y Oyanedel, 2018) que permitan ampliar la creación artística visual hacia otros campos que enriquezcan el acervo experiencial de futuros profesores/as en artes visuales.

No obstante, y ante la necesidad de fortalecer la formación inicial docente en cada una de las disciplinas del curriculum escolar chileno, la creación del Sistema de Desarrollo Profesional Docente en Chile (Ley n $\left.{ }^{\circ} 20.903,2016\right)$ espera mejorar el desarrollo profesional y condiciones laborales del profesorado. Siendo la idoneidad disciplinar del profesorado y el tipo de formación que poseen quienes enseñan en 
el aula uno de sus primeros temas a considerar, según el Marco para la Buena Enseñanza (CPEIP, 2008). Contemplando para ello tres competencias esenciales: dominio del contenido disciplinar, dominio de la didáctica del área que enseñan y habilidades socioemocionales que le permitan construir un clima de aula que promueva el aprendizaje (Medeiros, Gómez, Sánchez, y Orrego, 2018).

Bajo éste panorama, recae sobre la formación inicial docente en artes visuales en Chile, un fuerte desarrollo de competencias propias de su disciplina. Disciplina que contrariamente a limitar la creación eminentemente en torno a lo visual, se abre a otros lenguajes de creación artística que dialogan con la práctica artística contemporánea. De hecho, el énfasis curricular de la asignatura de artes visuales tras su promulgación a fines del siglo XX, ha promovido prácticas artísticas tales como la instalación, la video-creación, la performace y net art, entre otros. Enmarcando las artes visuales bajo un ámbito plural de creación (Errázuriz, 2006) en diálogo constante con otros campos disciplinares.

Para Tejo (2017), al igual que Santos y Mesas (2018), el cuerpo comporta un rasgo interdisciplinar en cuanto dispositivo didáctico destinado al aprendizaje no tan solo de las artes visuales, sino además de otras disciplinas y lenguajes de expresión artística. Claro ejemplo de ello ha quedado graficado en el estrecho vinculo entre artes visuales y su tensión con factores sociales, culturales y politicos desde la sociología del arte (Eco, 2010; Gombrich,2004; Hauser, 2016). Asi como además, a partir de la relación estrecha entre cuerpo y mente desde la neurociencia y la estética (Cinzia, y Vittorio, 2009).

En el ámbito de las Humanidades el cuerpo cobra especial interés desde el planteamiento teórico del cuerpo político, comprendiendo el cuerpo como metáfora de la política (Foucault, 2009; Sennet, 2006). En el ámbito de las Ciencias Sociales, la subjetivización y corporeización de la experiencia profundiza en la construcción de la identidad profesional en programas de formación inicial (Arévalo et. al 2016; Castro y Farina, 2015; González y Martínez, 2018). Y en el ámbito de las Ciencias de la Salud, el cuerpo se comprende como soporte para la cognición corporeizada o embodiment cognition, bajo los estudios de la neurociencias. Entrelazando íntimamente la cognición humana con el cuerpo (Tran et al., 2017), en tanto el cuerpo es asumido como dispositivo sobre el cual se piensa y habita en él (Seitz, 2000). 


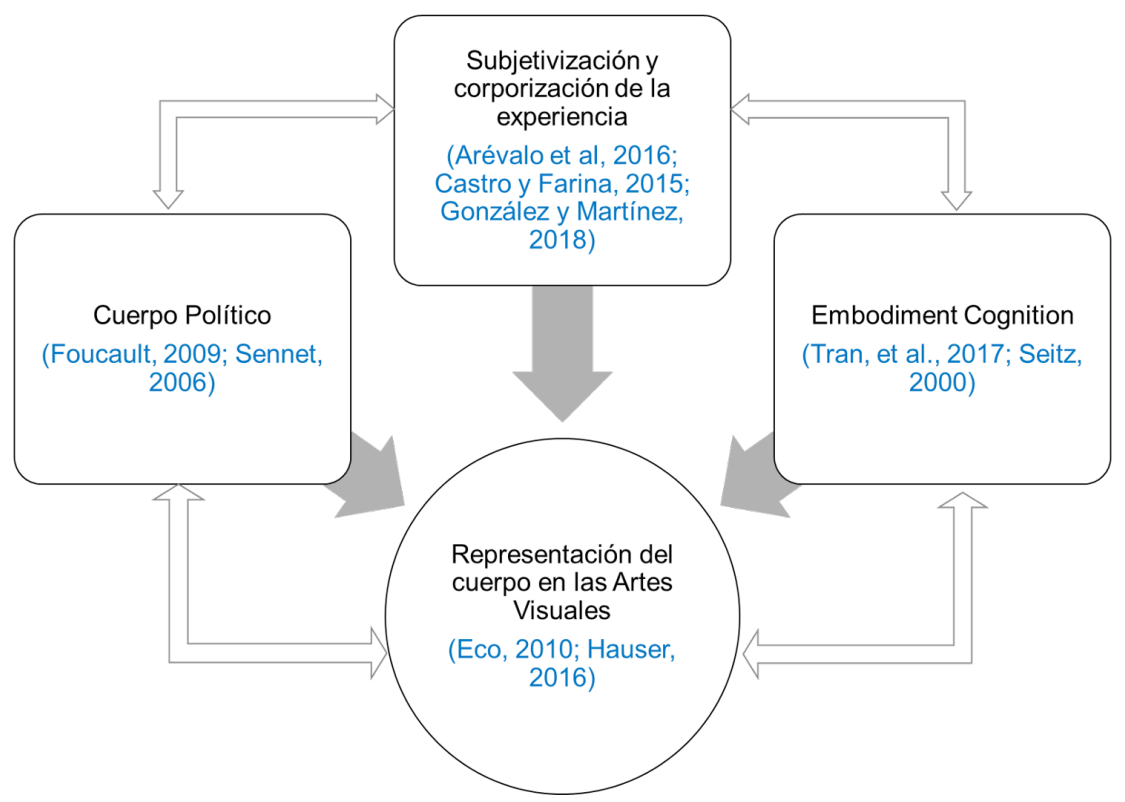

Figura 1. Relación teórica interdisciplinar del cuerpo, desde las artes visuales. Fuente de elaboración propia.

A partir de los antecedentes anteriormente expuestos, se define el siguiente objetivo principal mediante una experiencia pedagógica desarrollada al interior de un programa de formación de profesores/as en artes visuales en Chile, cuyo futuro desempeño laboral son los niveles de enseñanza secundaria: Reflexionar teóricamente en torno al cuerpo y sus posibilidades pedagógicas, a partir de la implementación de estrategias de enseñanza y aprendizaje de las artes visuales que involucran la práctica corporal como dispositivo didáctico.

\section{Métodología}

Al interior de un programa de formación de profesores/as en artes visuales en Chile, se implementan los siguientes tres talleres en torno al cuerpo y su relación teórico/ práctica con las artes visuales.

\section{Taller Cuerpo Individual / Estático \\ 2. Taller Tránsito del Cuerpo Estático / Dinámico \\ 3. Taller Cuerpo Colectivo / Dinámico}

Talleres que entrelazan respectivamente los planteamientos teóricos del cuerpo político, la subjetivización corporeizada de la experiencia y la cognición corporeizada o embodiment cognition.

Para ello, se tiene en consideración una metodología basada en "Proyectos de Aprendizaje Expresivos" desarrollada por Prat y Brunicardi (2017) en los ámbitos de la formación de profesores/as en educación física y del deporte. Implementando de este modo con futuros/as profesores/as de artes visuales, estrategias interdisciplinares 
CORTES, GRINSPUN, MEDINA \& OYARZÚN / El cuerpo como dispositivo didáctico en la formación inicial docente en artes visuales para enseñanza secundaria

de enseñanza-aprendizaje del cuerpo bajo un modelo conformado por tres fases temporales: fase inicial, fase intermedia y fase de cierre (Prat y Brunicardi, 2017) (figura 2).

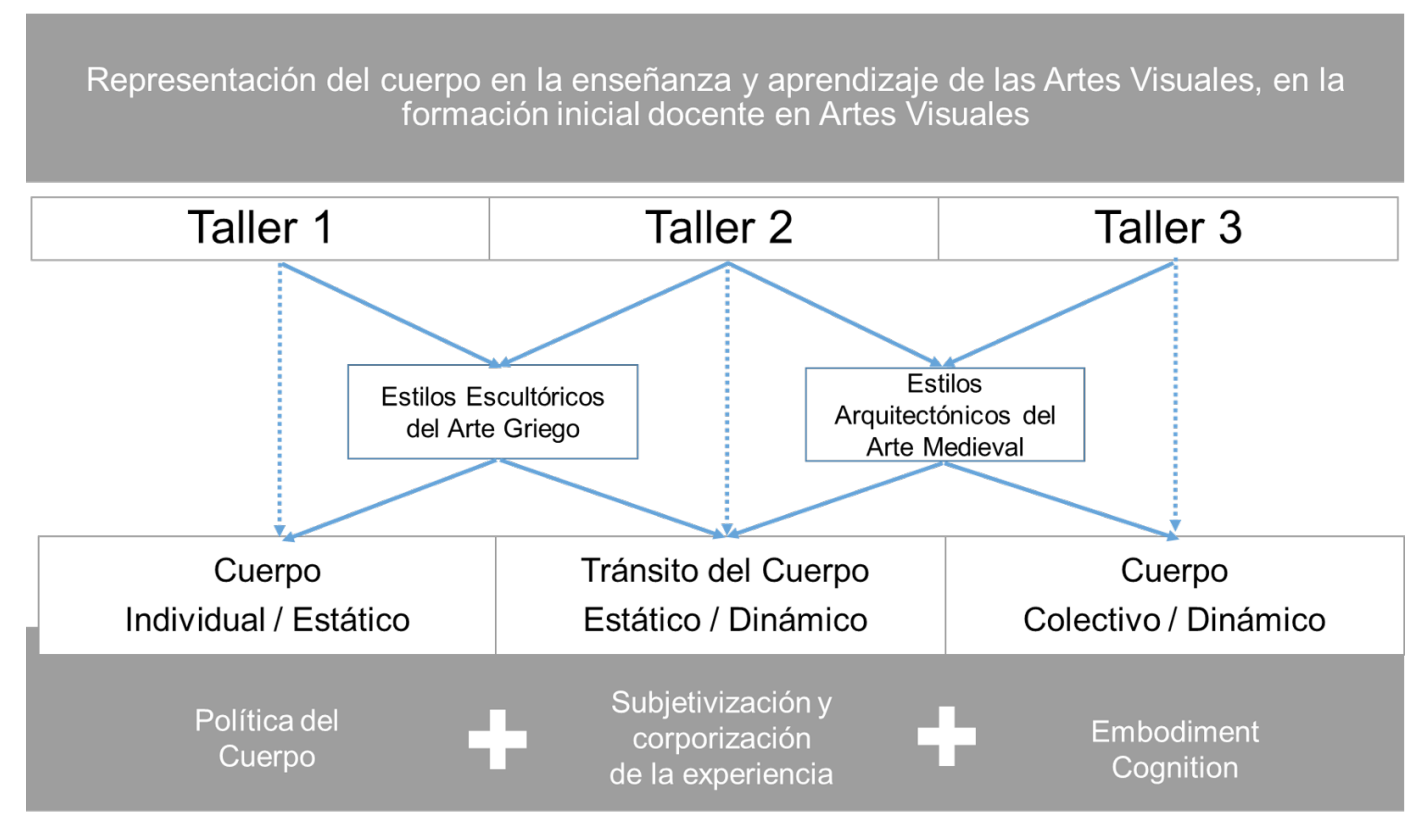

Figura 2. Organización temporal de los talleres. Fuente de elaboración propia.

De este modo, durante un periodo académico conformado por 5 meses, el cuerpo como dispositivo didáctico es propuesto secuencialmente abordando cada uno de los ambitos teóricos señalados anteriormente.

En primer lugar una fase inicial, para la representación corporal estática e individual de esculturas griegas para el abordaje de la política del cuerpo. En segundo lugar una fase intermedia, en donde el cuerpo transita desde su estado individual y estático, hacia la subjetivización de la experiencia corporeizada a partir de su relación dinámica con diferentes estilos de arte griego. Y en tercer lugar una fase de cierre, en donde el cuerpo es objeto de experimentación e improvisación mediante performance colectivas y dinámicas para abordar dos estilos arquitectónicos medievales, bajo la teoria de la cognición corporeizada.

Fases con sus respetivos talleres, en donde se hacen eco las orientaciones didácticas explicitadas en los programas y planes de estudios de las Artes Visuales de enseñanza secundaria en Chile. Considerando al interior de cada taller, una estructurada temporal y secuenciación didáctica del cuerpo en tres momentos: inicio, desarrollo y cierre (Martinic y Villalta, 2015). 


\section{Descripción Taller Cuerpo Individual / Estático}

El primer taller aborda el lenguaje escultórico a partir del cuerpo individual como metáfora política de dominio social y cultural.

Su objetivo específico consiste en relacionar las artes visuales con la política, a través de la representación corporal de diferentes estilos escultóricos, para comprender el cuerpo como dispositivo didáctico.

Iniciada la actividad, se abordan componentes estilísticos de los periodos escultóricos del arte en Grecia, bajo un enfoque socio-crítico. Identificando en los periodos Arcaico, Clásico, Ilustrado y Helenístico, los rasgos políticos, sociales y culturales, en diferentes representaciones corporales.

Durante el desarrollo de la actividad, cada profesional en formación escoge y representa corporalmente una pieza escultórica, según los criterios estilísticos de los diferentes periodos históricos. Empleando diversas vestimentas y maquillaje blanco con el objeto de emular la materialidad del mármol y resaltar rasgos físicos y anatómicos de cada pieza escultórica representada.

La actividad contempla un máximo de tres minutos por cada participante para escenificar estáticamente los periodos escultóricos, según sus criterios estilísticos propios.Escenificaciónregistradafotográficamenteparasuposterioranálisis(figura3).

Finalizada la actividad, la secuencia de imágenes son analizadas bajo los planteamientos del cuerpo político como un todo absoluto, según la teoría política del organicismo (Martínez, 2006). A partir de lo cual, cada periodo escultórico es reflexionado en torno a la estructura orgánica del cuerpo y aspectos políticos, culturales y sociales de cada periodo histórico en estudio (Hauser, 2016). Concluyendo que el orden social regido por normas culturales constituyen el soporte de construcción cultural y artística visual del cuerpo (Micieli, 2007), según la política imperante en cada periodo histórico (Sennett, 2006).

Bajo estos términos, los diferentes estilos escultóricos del arte griego conservan directa relación con campo político del cuerpo (Foucault (2009). Por ejemplo, la rigidez del periodo arcaico es reflejo de gobiernos tiránicos que detentan y heredan el poder por razones de clase El equilibrio geométrico del periodo clásico, refleja el intento por forjar un sistema democrático en donde una elite dirigente es escogida por ciudadanos que excluye a esclavos y mujeres. El tratamiento corporal de la belleza ideal durante el periodo ilustrado, refleja el delicado equilibrio entre el canon y lo individual. Y la exacerbación de gestos corporales durante el periodo helenístico, son reflejo de la perdida de gran parte la antigua conexión con la religión y la magia (Gombrich, 2004, Hauser, 2016). 


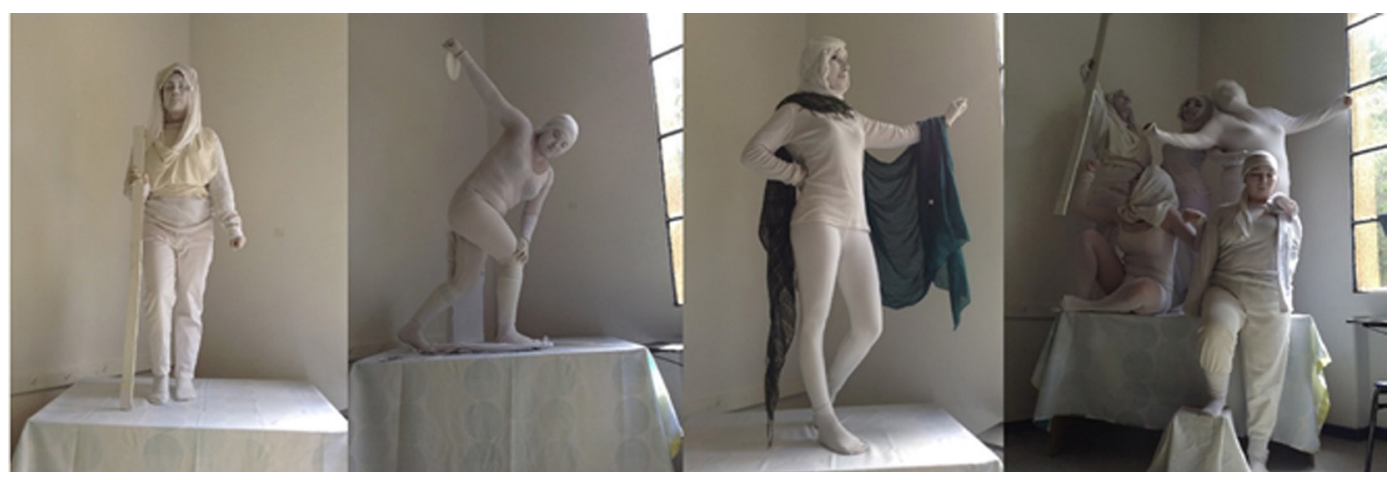

Figura 3. Secuencia de representación corporal de periodos escultóricos del Arte en Grecia. Fuente de elaboración propia.

\section{Taller Tránsito del Cuerpo Estático / Dinámico}

Considerando los aprendizajes previos de los periodos escultóricos del arte griego, a través de su representación corporal, se transita hacia un segundo taller centrado en la construcción de la identidad profesional.

Su objetivo específico consiste en articular interdisciplinarmente el lenguaje visual, musical y corporal, mediante la construcción de relatos audiovisuales, en torno a la evolución de los estilos artísticos precedentes.

Iniciada la actividad, se enfatiza la importancia de la identidad profesional docente en artes visuales a partir del cuerpo. Reflexión teórica que permite canalizar la práctica del aprendizaje corporizado, para la representación del tránsito de un estilo escultórico al otro.

Para el desarrollo de la actividad, los/las profesionales en formación se organizan en parejas de trabajo para diseñar propuestas de relatos corporizados. Construyendo provisionalmente al interior de la sala de clases, una escenografía de 3 metros de alto, 5 metros de ancho por 3 metros de fondo. Generando una ambientación propicia para relatos corporeizados sobre un fondo negro, el cual contrasta con el blanco de las esculturas humanas en movimiento. Todo acompañado de diversos fragmentos musicales escogidos a libre elección, según intereses de cada participante. Concluyendo con representaciones corporeizadas que evidencian el tránsito dinámico de los periodos escultóricos del arte griego. Articulando el lenguaje visual, corporal y musical para su registro audiovisual y posterior análisis (figura 4).

Finalizada la actividad, los/las profesionales destacan que el uso del propio cuerpo permite pensar en él (Seitz, 2000). Reflexionando en torno a experiencias encarnadas como soporte representacional y relato textual (Castro y Farina, 2015), cuyo saber disciplinar especifico de la Artes Visuales se articula con el lenguaje corporal y musical. Conectándose a nivel teórico y práctico con el aprendizaje corporeizado o 
embodiment, referido a la idea de que la cognición humana no se puede separar del cuerpo (Tran, et al., 2017).
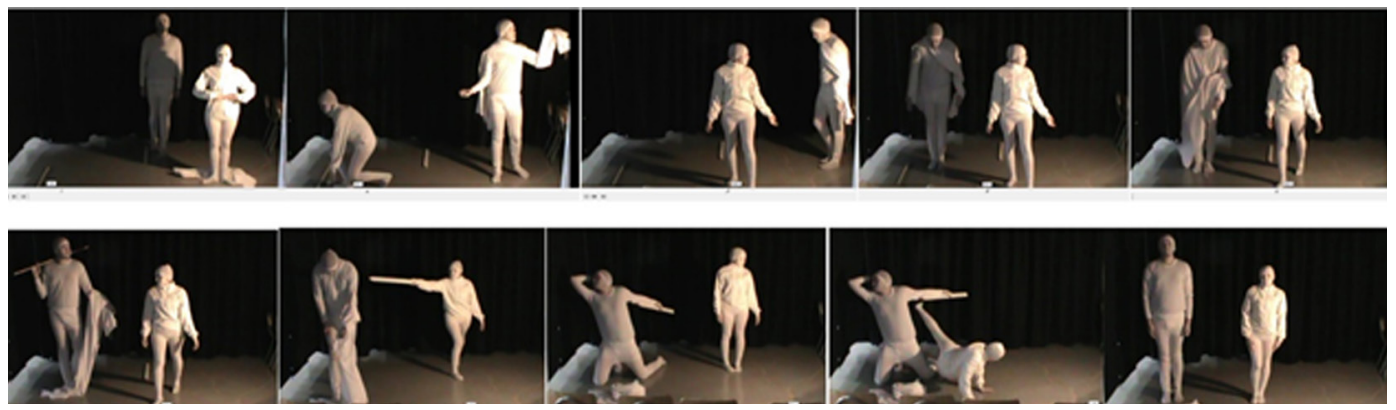

Figura 4. Registro audiovisual de relato corporizado. Fuente de elaboración propia.

\section{Taller Cuerpo Colectivo / Dinámico}

La implementación del tercer taller aborda la problemática del cuerpo individual y colectivo, subvirtiendo las fronteras espaciales de la sala de clase, interrumpiendo y tensionando la cotidianeidad mediante acciones corporeizadas o performance colectivas (Barría, 2014).

Su objetivo específico consiste en integrar los espacios marginales y espacios normativos, resignificando el tránsito corporeizado, a partir de estilos arquitectónicos del arte medieval.

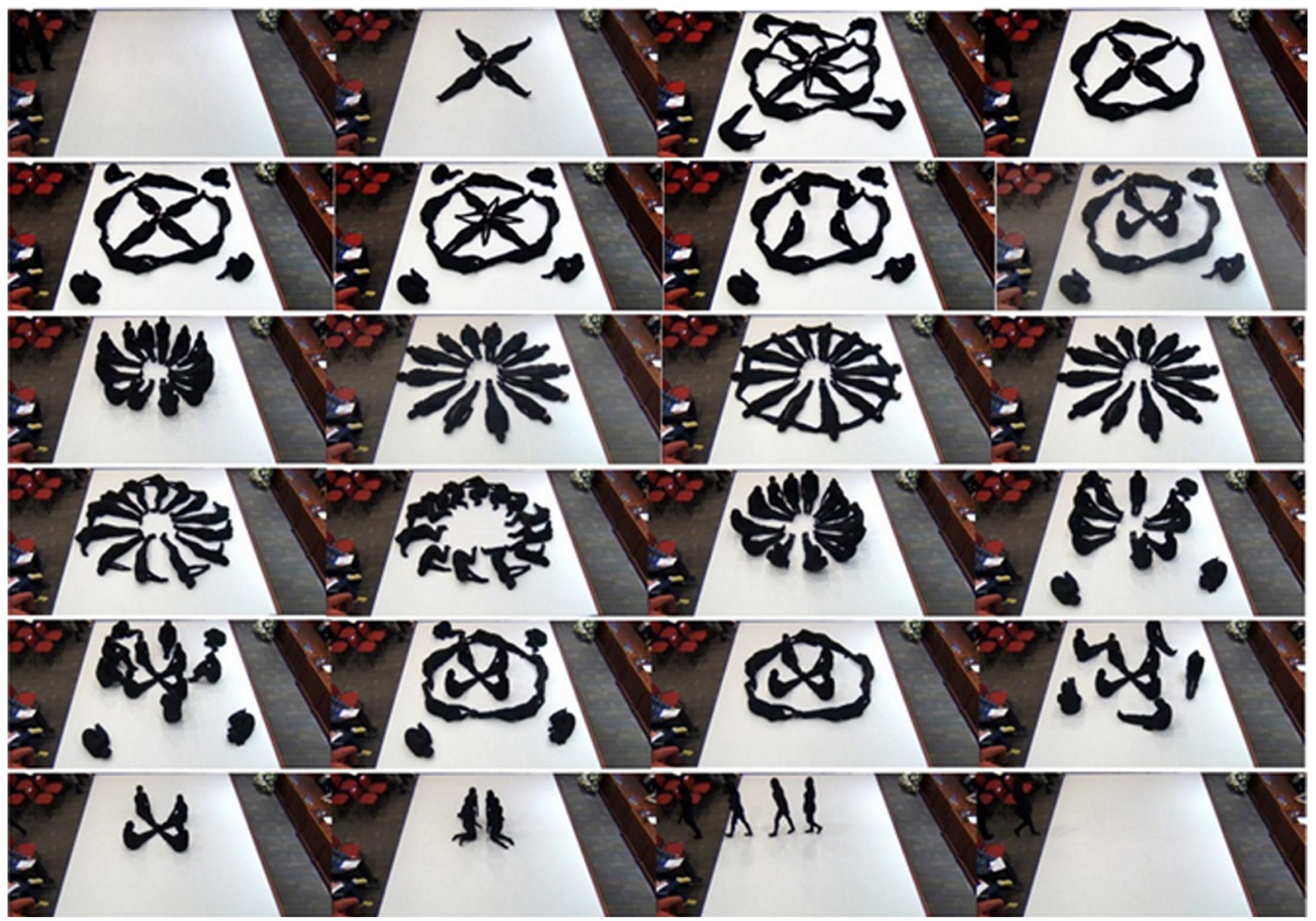

Figura 5. Registro audiovisual de ejercicio de representación corporeizada de vidrieras medievales. Fuente de elaboración propia. 
Iniciada la actividad se revisa y consulta la progresión estilística del periodo románico al periodo gótico, en construcciones arquitectónicas. Haciendo especial énfasis en la homologación del cuerpo individual/colectivo con el diseño y construcciones arquitectónicas de arcos de medio punto románico y arcos ojivales del gótico.

A partir del desplazamiento del cuerpo colectivo de los/las participantes, se dinamiza teóricamente la relación corporeizada de la performace con aspectos sociales y políticos de ambos periodos.

Para el desarrollo de la actividad, se dispone de dos espacios. Un primer espacio al interior de la sala de clases, utilizado para los ensayos. Y un segundo espacio, correspondiente a un auditorio destinado para un total aproximado de 200 personas, para su presentación final.

En ambos casos, durante ensayo y presentación final, el grupo de participantes emplea vestimentas negras, desplazándose coordinadamente sobre un lienzo de covernil blanco, de 5 metros de ancho por 20 metros de largo, extendido en el suelo de cada espacio.

Para su posterior análisis, cada performance colectiva es registrada audiovisualmente mediante cámara de video instaladas en el techo de su respectivo espacio, a una altura aproximada de 5 metros (figura 5).

Durante la etapa de análisis se reflexiona en torno al nulo aprecio y valoración del cuerpo anatómico y carnal durante la Edad Media. Subsumiendo simbólicamente el cuerpo individual ante el diseño y construcción corporeizada de estilos arquitectónicos que transitan de un estilo al otro. De hecho, el cuerpo durante la Edad Media sufre extrañamiento, se habita en él, para no ser en él (Eco, 2010).

Evidenciando a través de cada performance, la falta de valoración hacia la corporeidad que proviene del aprecio a lo espiritual durante la edad media. Ya que el cuerpo es el sostenido y el espíritu el sostenedor. Reflejado en el cuerpo colectivo y su vestimenta negra, contrastado con el blanco de la superficie que soporta cada acción performática. Experimentando una serie de competencias didácticas, centradas en: "el aprendizaje, inteligencias múltiples, sujeto colectivo, educación como diálogo, ciudadanía, creatividad, cambio de percepciones, valores, sostenibilidad, interdependencia, conectividad, interdisciplinariedad, transversalidad, multiculturalidad, nuevas tecnologías y calidad con equidad" (Motos, 2005, p.87).

\section{Discusión Teórica}

En base a la descripción de la implementación de los talleres, es posible entablar una discusión teórica que abre posibilidades interdisciplinares para el aprendizaje 
corporeizado de las artes visuales para enseñanza secundaria. Cuyas referencias bibliográficas permiten reflexionar en torno a la política del cuerpo, la corporeización de la identidad profesional y la cognición corporeizada.

\section{Política del Cuerpo}

Durante el primer taller, la política del cuerpo activó la representación corporeizada de diferentes piezas escultóricas griegas, operando como metáfora progresiva de cada estilo artístico: "desde la manera dura de la escultura arcaica hasta la suavidad y la dulzura de los maestros del siglo IV, para ilustrar el progreso de la oratoria latina y su cambio de carácter, desde el vigor rústico al liso pulimiento" (Gombrich, 2004, p.6).

La representación del Auriga de Delfos (475 a.c.) del periodo Arcaico, reflejó posturas corporales rígidas, composiciones hieráticas, geométricas y simétricas. Reflejo del predominio de un estado rígido representado escultóricamente bajo rígidas normas geométricas: "Los tiranos emplean el arte no sólo como medio de adquirir su gloria y como instrumento de propaganda, sino también como opio para aturdir a sus súbditos" (Hauser, 2016, p.100).

La representación de El Discóbolo (Mirón, 450 a.c.) del periodo Clásico, articuló equilibradamente la rigidez de la estructura social con la necesidad individual y natural de observación bajo una contradicción sociológica: "La democracia con su liberalismo e individualismo, y el estilo clásico, con su severidad y esquematismo, parece, en el primer momento inconciliables [...] contradictoria relación de la idea democrática con el problema del individualismo" (Hauser, 2016, p.108). De este modo, el Mirón, al igual que la generación de Fidias y la posterior de Praxíteles "practican una especie de equilibrio entre la representación realista de la belleza, en especial la de las formas humanas [...] y la adhesión a un canon (kanon) específico, por analogía con la regla (nómos) utilizada en las composiciones musicales" (Eco, 2010, p.45).

La representación escultórica del periodo Ilustrado, evidenció la concepción naturalista del cuerpo despojado de normas geométricas como metáfora del pensamiento filosófico predominante en manos de los sofistas. Por ejemplo, el Apolo Belvedere (350 a.c.), copia romana en mármol de su original (224 a.c.) representa el concepto de belleza ideal que invade la construcción del cuerpo en donde lo modélico y lo individual se mantienen en un nuevo y delicado equilibrio. Posturas relajadas que en nada ofenden su dignidad (Gombrich, 2004), y que no poseen nada aristocráticamente rígido, produciendo más bien la impresión de un bailarín en lugar de un atleta (Hauser, 2016).

Finalmente el Periodo Helenístico, caracterizado por la exacerbación de gestos corporales acompañados de desequilibrios y desproporciones en sus representaciones 
escultóricas, quedó reflejado en composiciones saturadas y recargadas. En donde el cuerpo pierde gran parte su antigua conexión con la religión y la magia en relación al desarrollo de las etapas precedentes, ya que los artistas se preocuparon por los problemas intrínsecos del arte. Así por ejemplo, uno de sus conjuntos escultóricos más importantes constituye una grave violación a las reglas precedentes en el Laocoonte, cuya "escena es dinámica, descrita de forma dramática y no simplificada en absoluto por el autor" (Eco, 2010, p.45).

\section{Subjetivación y corporeización de la experiencia}

Tras el desarrollo del segundo Taller, es posible señalar al igual que en la pedagogía teatral, que la propia experiencia corporeizada permitió indagar en la memoria corporal de cada profesional en formación. Taller en donde la colaboración conjunta entre pares, vinculados a prácticas artísticas situadas en la escuela, permitió establecer lazos de comunicación intersubjetiva entre los/las participantes (Alfonso, 2012).

Ampliando la mirada sobre la corporalidad en artes visuales y la subjetividad corporeizada: "[...] apela entonces a que el cuerpo, los sentidos, la sensibilidad, el movimiento corporal, la percepción sensorial, etc., son experiencias que tienen su sustrato en la propia corporalidad y se constituyen en una instancia fundamental para la formación humana" (Gallo, 2009, p.238).

Relatos corporales sobre estrategias corporeizadas individuales y colaborativas que expresaron el tránsito de un estilo a otro. Entablando una relación inter-subjetiva entre los/las participantes, interrelacionando autobiografía, emocionalidad, movimiento corporal, conciencia corporal, comunicación y expresión corporal.

Adscribiéndose de este modo a lo ya formulado por Marshall (2014), respecto de las nuevas formas de pensar el arte, cuyas finalidades y métodos han cambiado la forma en que el arte se enseña y se realiza en la escuela. Cuestionando principalmente la fabricación de objetos estéticos e imágenes, el desarrollo de un estilo personal, o el dominio de la técnica. Dando lugar a nuevas experiencias corporeizadas a partir de relatos que permiten construir subjetiva e intersubjetivamente la identidad docente, en donde los lenguajes musicales y visuales confluyen en el cuerpo de profesionales en formación.

\section{Cognición corporeizada}

El tercer y último Taller, escenificó una Performance colectiva, sincronizando ritmo y desplazamiento corporal, de acuerdo a un tempo musical. Instando a cada participante ante un acto colectivo in-situ, homologando el cuerpo como soporte de estructuras arquitectónicas para representar coordinadamente los tránsitos de estilos arquitectónicos medievales: románico y gótico. 
Al respecto, cabe señalar que todas las culturas humanas poseen alguna forma musical con un pulso, un pulso percibido como periódico que guía el movimiento de los oyentes, que en el caso de los/las profesionales en formación utilizan para coordinar sus acciones (Brown y Jordania, 2013). El ritmo se encuentra asociado al movimiento, lo que ha sido comprobado al observar que el escuchar una secuencia rítmica, incluso sin realizar un acto motor, activa las mismas regiones motoras que se activarían al moverse (Levitin, Grahn, y London, 2017).

Sincronización rítmica que involucra procesos complejos que incluyen una red de áreas y regiones cerebrales como las cortezas auditivas, motoras y prefrontales (Chen, Penhune y Zatorre, 2008), requeridas para la sincronización temporal del ritmo y la fina precisión temporal del sistema auditivo (Tierney y Kraus, 2013).

Bajo éstos términos, ésta experiencia colaborativa cobra especial relevancia producto de su fuerte componente interdisciplinar. En donde la capacidad de sincronización del movimiento desde la música es transferible no tan solo a estudiantes de enseñanza secundaria, sino además, a niños y niñas en etapas de educación preescolar (Martín, 2005). Ello debido a que niños y niñas logran moverse rítmicamente en relación a la música (Zentner y Eerola, 2010) desarrollando una capacidad que va mejorando a lo largo de los años (Eerola, Luck y Toiviainen, 2006).

Capacidad que no tan solo se desarrolla en actividades de expresión artística, sino además en actividades de lectura. De hecho niños y niñas con dificultades de lectura presentan igualmente dificultades para sincronizarse con un ritmo. Ello debido a una correlación positiva entre la capacidad de seguir un ritmo y las habilidades de lectura (Tierney y Kraus, 2013).

Razón por la cual, ésta actividad desarrollada al interior de la formación de profesores y profesoras en artes visuales, se proyecta hacia otros ámbitos disciplinares. Abordando no tan solo contenidos específicos de las artes visuales, sino además el desarrollo de habilidades cognitivas relevantes que conservan un correlato con la sincronización y el ritmo.

\section{Conclusión}

Se concluye que estrategias corporeizadas de enseñanza y aprendizaje de las artes visuales, al interior de la formación de profesores/as en artes visuales, conlleva un proceso de articulación interdisciplinar de aspectos teóricos y prácticos que se enriquecen a partir del lenguaje corporal, la sincronización ritmica y habilidades tanto de relato corporeizado como de lectura.

De hecho, los estilos escultóricos del arte griego y estilos arquitectónicos del arte medieval, más allá de su especificidad disciplinar, constituyen una oportunidad para entablar relaciones con otras asignaturas del currículo escolar chileno. Integrando 
los lenguajes visual, corporal y musical; en donde el cuerpo emerge transversalmente como un dispositivo didáctico en las asignaturas de artes visuales, educación física, educación musical e historia.

Emergiendo conexiones teóricas, entre las cuales cabe destacar la relación y evolución entre las diversas artes y las sociedades de las que surgen, descritas por el teórico sociólogo del arte Arnold Hauser (2016), añadiendo la enseñanza corporeizada como parte de las nuevas estrategias didácticas. A raíz de lo cual, emergen los siguientes talleres de enseñanza corporeizada para la formación de profesores/as en artes visuales:

- Taller 1. El teatro y el cine primitivo: En los primeros años de existencia el cine empleaba técnicas teatrales, tanto del teatro del siglo XIX como de géneros teatrales como la farsa, tal y cómo la tradición ha perpetuado desde Plauto y Terencio, y la "Commedia dell' arte" resucitados por el cine primitivo. Tal y como explica André Bazin (2014, p.157), considerado uno de los más importantes críticos y teóricos cinematográficos de la historia del cine, "puede verse también cómo la influencia tan inconsciente como inconfesada del repertorio y de las tradiciones teatrales ha tenido una influencia decisiva sobre los géneros cinematográficos". Esta influencia en el cine, certeramente descrita por Bazin, es comprobable analizando el cine mudo primitivo, en el que imperan las técnicas heredadas del teatro: punto de vista único y fijo, filmación predominantemente en interiores, gestualidad de los actores y actrices exagerada, estructuras narrativas adoptadas del teatro etc.

- Taller 2. La novela y el cine clásico: La revolución de las estructuras del relato cinematográfico se debió en gran medida a la traslación, por parte de David Wark Griffith en la segunda década del s. XX, de las estructuras narrativas de la novela decimonónica, en concreto de la narrativa de Charles Dickens. En el estudio de las relaciones e influencias entre literatura y cine realizado por el crítico literario y cinematográfico Pere Gimferrer se evidencia que (1985, pp. 53-54): "la novela decimonónica (adoptada por Griffith) es heredera del poema épico, de la narrativa medieval y de la novela del Renacimiento. [...] el esquema griffithiano puede ser capaz de acoger [...] cualquier forma de relato anterior a esta época". Encontramos, por tanto, una evolución narrativa cinematográfica relacionada férreamente con estructuras literarias previas al nacimiento del cine, más allá de la influencia teatral, que determinan el desarrollo del cine hasta la actualidad.

- Taller 3. La novela modernista y el cine de vanguardias: En el arte cinematográfico han predominado, de forma muy mayoritaria, las estructuras narrativas de la novela decimonónica asentadas por Griffith, y que han experimentados variantes de las mismas a lo largo de la historia del cine. Como sentencia Gimferre (1985) asistimos a un divorcio entre la literatura 
heredera del modernismo y el cine, pues los experimentos narrativos de las vanguardias literarias fueron acogidos de forma minoritaria por las industrias cinematográficas. Podremos, aun así, señalar algunas secuencias o filmes más cercanos a esta narrativa que al modelo griffithiano, encuadrados en el cine de vanguardias o en el trabajo de cineastas concretos como Luis Buñuel, Ingmar Bergman, Marguerite Duras o Alain Resnais

\section{Referencias}

Alfonso, M. (2012). Aportes a la construccion de la identidad profesional del profesor de teatro. Folios, Revista de la Facultad de Humanidades Universidad Pedagógica Nacional 35, 3-15.

Arévalo, A., Fernández L1, B., Hidalgo, F., Lepe, Y., Miranda, C., Núñez, M., y Reyes, L. (2016). Corporalidades y narrativas docentes: un dispositivo metodológico para la investigación y formación de profesores. Estudios pedagógicos, 42(4), 223-242.

Barría, M. (2014). Intermitencias: Ensayos sobre performance, teatro y visualidad. Santiago de Chile: Editorial Universitaria.

Bazin, A. (2014). ¿Qué es el cine?. Barcelona: Ediciones Rialp.

Brown, S., and Jordania, J. (2013). Universals in the world's musics. Psychol. Music, 41, 229-248. https://doi.org/10.1177/0305735611425896

Cárdenas, R.; Lagos, I. y Figueroa, E. (2016). El profesorado de educación básica y su contribución a la enseñanza de las artes visuales en la escuela. Arte, Individuo y Sociedad, 28(3), 475-493.

Castro, J., y Farina, C. (2015). Hacia un cuerpo de la experiencia en la educación corporal. Revista Brasileira de Ciências do Esporte, 37(2), 179-184.

Chen, J.L, Penhune, V.B., Zatorre, R. (2008). Moving on Time: Brain Network for Auditory-Motor Synchronization is Modulated by Rhythm Complexity and Musical Training. Journal of Cognitive Neuroscience, 20(2), 226-239.

Cinzia, D. D., y Vittorio, G. (2009). Neuroaesthetics: a review. Current opinion in neurobiology, 19(6), 682-687.

Cortés, L.C. (2018). La performatividad en la acción pedagógica de profesores/as en formación en artes visuales. Atenea (Concepción), 518, 57-73. https://dx.doi. org/10.4067/S0718-04622018000200057

Cortés, L.C., y Grinspun, N. (2019). La importancia del cuerpo en las prácticas pedagógicas en Artes Visuales. Perspectiva Educacional, 58(3), 102-126. https:// dx.doi.org/10.4151/07189729-vol.58-iss.3-art.865 
CORTES, GRINSPUN, MEDINA \& OYARZÚN / El cuerpo como dispositivo didáctico en la formación inicial docente en artes visuales para enseñanza secundaria

CPEIP (2008). Marco para la Buena Enseñanza. Santiago de Chile: Ministerio de Educación. Recuperado el 05 de septiembre de 2019, de https://www.cpeip.cl/ marco-buena-ensenanza/

Eco, H. (2010). Historia de la Belleza. Barcelona: De Bolsillo.

Eerola, T., Luck, G. y Toiviainen, P. (2006). An investigation of pre-schoolers corporeal synchronization with music. In, $9^{\circ}$ International Conferencia on Musica Perception and Cognition. Alma Mater Studiorum University of Bologna (pp.472476). Bologna.

Errázuriz, L. H.(2006). Sensibilidad Estética. Un desafio pendiente en la educación Chilena. Santiago de Chile: Instituto de Estética, Pontificia Universidad Católica de Chile.

Foucault, M. (2009). Vigilar y Castigar. Nacimiento de la Prisión. Argentina: Siglo XXI.

Gallo, L. E. (2009). El cuerpo en la educación da qué pensar: perspectivas hacia una educación corporal. Estudios pedagógicos (Valdivia), 35(2), 232-242. doi:10.4067/ $\underline{\mathrm{S} 0718-07052009000200013}$

Gimferre, P. (1985). Cine y literatura. Barcelona: Ediciones Planeta.

Gombrich, E.H. (2004). La Historia del Arte. Madrid: Debate.

González, G., y Martínez, L. (2018). Los Diarios Corporales Docentes como Instrumentos de Reflexión y de Evaluación Formativa en el Prácticum de Formación Inicial del Profesorado. Estudios pedagógicos (Valdivia), 44(2), 185204. doi:10.4067/S0718-07052018000200185

Hauser, A. (2016). Historia social de la literatura y el arte I. Desde la prehistoria hasta el barroco. Madrid: Debolsillo.

Horn, S. (2009). Performance art at secondary level. International Journal of Art y Design Education, 28(2), 160-173.

Levitin, D. J., Grahn, J. A., y London, J. (2017). The Psychology of Music: Rhythm and Movement. The Annual Review of Psychology, 69, 51-75. doi:10.1146/annurevpsych-122216- 011740

Marshall, J. (2014). Transdisciplinarity and Art Integration: Toward a New Understanding of Art-Based Learning across the Curriculum. Studies in Art Education, 55(2), 104-127. doi:10.1080/00393541.2014.11518922

Martín, M. (2005). Del movimiento a la danza en la educación musical. Educatio Siglo XXI: Revista de La Facultad de Educación, 23, 125-139. 
Martínez, S. (2006). El cuerpo político. En Res Pvblica Litterarvm, Documentos de trabajo del grupo de investigación "Nomos" (pp.3-7). Madrid: Instituto de Estudios Clásicos, Lucio Anneo Séneca.

Martinic, S., y Villalta, M. (2015). La gestión del tiempo en la sala de clases y los rendimientos escolares en escuelas con jornada completa en Chile. Perfiles educativos, 37(147), 28-49.

Medeiros, M. P., Gómez, C., Sánchez, M. J., y Orrego, V. (2018). Idoneidad disciplinar de los profesores y mercado de horas docentes en Chile. Calidad en la educación, 48, 50-95.

Micieli, C. (2007) El cuerpo como construcción cultural. Aistehsis, 42 (2007), 4769. Recuperado de http://revistaaisthesis.uc.cl/index.php/rait/article/view/449

Motos, T. (2005). Desarrollo de la expresión para ser y hacer creativos. En Gervilla Castillo, Ángeles y Bernál Vázquez, Julia (Dirección), Creatividad: aspectos psicológicos, educativos y sociales (pp. 421-433). Málaga: Editorial Dykinson.

Orbeta, A., y Oyanedel, R. (2018). En vías de desaparición. Antecedentes para entender la disminución de las artes en la formación inicial docente de educación primaria en Chile. Arte, Individuo y Sociedad, 30(2), 375. doi:10.5209/ARIS. 57622

Prat, M. T. A., y Brunicardi, D. P. (2017). Las luces de la expresión corporal: Ventajas y posibilidades de los Proyectos de Aprendizaje Expresivos. Educación Física en Secundaria. Retos: nuevas tendencias en educación física, deporte y recreación, 31, 232-237.

Santos Sánchez-Guzmán, E. y Mesas Escobar, E. C. (2018). La creatividad integrada desde el análisis de experiencias artísticas con personas con capacidades diversas en espacios académicos. Revista Complutense de Educación, 29(3), 773789. doi:10.5209/RCED.53958

Seitz, A (2000). The Bodily Basis of Thought. New Ideas in Psychology, 18, 23-40.

Sennet, R. (2006). Carne y Piedra: El Cuerpo y la Ciudad en la Civilización Occidental. Alianza: Madrid.

Ley $\mathrm{n}^{\circ}$ 20.903, Crea el sistema de desarrollo profesional docente y modifica otras normas. Biblioteca del Congreso Nacional de Chile de 4 de marzo de 2016. Recuperada de https://www.leychile.cl/N?i=1087343yf=2016-04-01yp=

Tejo, C. (2017). Proyectos de arte de acción: análisis de una experiencia pedagógica. Arte, Individuo y Sociedad, 1(1), 203-217. doi:10.5209/ARIS.47320 
CORTES, GRINSPUN, MEDINA \& OYARZÚN / El cuerpo como dispositivo didáctico en la formación inicial docente en artes visuales para enseñanza secundaria

Tierney, A. T., y Kraus, N. (2013). The ability to tap to a beat relates to cognitive, linguistic, and perceptual skills. Brain and Language, 124(3), 225-231. doi:10.1016/j.bandl.2012.12.014

Tran, C., Smith, B., y Buschkuehl, M. (2017). Support of mathematical thinking through embodied cognition: Nondigital and digital approaches. Cognitive Research: Principles and Implications, 2(1), 16.

Zentner, M., y Eerola, T. (2010). Rhythmic engagement with music in infancy. Proceedings of the National Academy of Sciences, 107(13), 5768-5773. doi:10.1073/ pnas. 1000121107. 